\title{
Cost-effective therapeutic hypothermia treatment device for hypoxic ischemic encephalopathy
}

This article was published in the following Dove Press journal:

Medical Devices: Evidence and Research

31 December 2012

Number of times this article has been viewed

\begin{abstract}
John J Kim ${ }^{1,2}$
Nathan Buchbinder ${ }^{1, \dagger}$

Simon Ammanuel ${ }^{1,4,5, \dagger}$

Robert Kim ${ }^{1, \dagger}$

Erika Moore'

Neil O'Donnell'

Jennifer K Lee ${ }^{3}$

Ewa Kulikowicz ${ }^{3}$

Soumyadipta Acharya'

Robert H Allen ${ }^{1,9}$

Ryan W Lee ${ }^{6,7}$

Michael V Johnston ${ }^{4-8}$

'Department of Biomedical Engineering, Whiting School of Engineering, The Johns Hopkins University, ${ }^{2}$ The James Buchanan Brady Urological Institute, Department of Urology, The Johns Hopkins University School of Medicine, ${ }^{3}$ Department of Anesthesia and Critical Care Medicine, Johns Hopkins University, ${ }^{4}$ Kennedy Krieger Institute, ${ }^{5}$ Hugo W Moser Research Institute, ${ }^{6}$ Department of Neurology, ${ }^{7}$ Department of Pediatrics, ${ }^{8}$ Department of Physical Medicine and Rehabilitation Johns Hopkins University School of Medicine, Baltimore, MD; ' Department of Gynecology and Obstetrics, Johns Hopkins University School of Medicine, Baltimore, MD, USA

tThese authors contributed equally to this work
\end{abstract}

Correspondence: John J Kim The Whitaker Biomedical Engineering Institute, Department of Biomedical Engineering, $3400 \mathrm{~N}$ Charles St,

Baltimore, MD 21218, USA

Tel +l 8052208765

$\mathrm{Fax}+\mathrm{I} 4439239317$

Email jkim324@jhu.edu
Abstract: Despite recent advances in neonatal care and monitoring, asphyxia globally accounts for $23 \%$ of the 4 million annual deaths of newborns, and leads to hypoxic-ischemic encephalopathy (HIE). Occurring in five of 1000 live-born infants globally and even more in developing countries, $\mathrm{HIE}$ is a serious problem that causes death in $25 \%-50 \%$ of affected neonates and neurological disability to at least $25 \%$ of survivors. In order to prevent the damage caused by HIE, our invention provides an effective whole-body cooling of the neonates by utilizing evaporation and an endothermic reaction. Our device is composed of basic electronics, clay pots, sand, and urea-based instant cold pack powder. A larger clay pot, lined with nearly $5 \mathrm{~cm}$ of sand, contains a smaller pot, where the neonate will be placed for therapeutic treatment. When the sand is mixed with instant cold pack urea powder and wetted with water, the device can extract heat from inside to outside and maintain the inner pot at $17^{\circ} \mathrm{C}$ for more than 24 hours with monitoring by LED lights and thermistors. Using a piglet model, we confirmed that our device fits the specific parameters of therapeutic hypothermia, lowering the body temperature to $33.5^{\circ} \mathrm{C}$ with a $1^{\circ} \mathrm{C}$ margin of error. After the therapeutic hypothermia treatment, warming is regulated by adjusting the amount of water added and the location of baby inside the device. Our invention uniquely limits the amount of electricity required to power and operate the device compared with current expensive and high-tech devices available in the United States. Our device costs a maximum of 40 dollars and is simple enough to be used in neonatal intensive care units in developing countries.

Keywords: therapeutic hypothermia, evaporative cooling, hypoxic ischemic encephalopathy, birth asphyxia, neuroprotection

\section{Introduction}

Hypoxic ischemic encephalopathy (HIE) is a serious condition that leads to death and disability in neonates due to oxygen deficiency in brain. Asphyxia in neonates can be caused by a variety of factors, including maternal malnutrition, placental abruption, cord prolapse, and uterine rupture. ${ }^{1}$ On a global scale, between $50 \%$ and $89 \%$ of infants who suffer from severe HIE die, while many of the survivors are subject to cerebral or neural related disorders. Additionally, there is a 20\%-37\% mortality and morbidity in those diagnosed with moderate HIE. ${ }^{2,3}$ Because of the morbidity and mortality associated with HIE, it, has become a major concern worldwide, and the high chances of a poor outcome for those suffering from the disease suggest a significant need for improved treatment. This is especially true in developing countries, where the rate of HIE is as high as $1.5 \%$ in newborns. ${ }^{4}$

Studies have shown that use of therapeutic hypothermia not only reduces the risk of death but also the possibility of long-term disability for infants who survive submit your manuscript | www.dovepress.com

Dovepress

http://dx.doi.org/10.2147/MDER.S39254
Medical Devices: Evidence and Research 2013:6 I-10

(C) $2013 \mathrm{Kim}$ et al, publisher and licensee Dove Medical Press Ltd. This is an Open Access article which permits unrestricted noncommercial use, provided the original work is properly cited. 
birth asphyxia. ${ }^{6-11}$ By slowing down the formation of free radicals and preventing apoptosis and necrosis in neurons, hypothermia has been demonstrated to be a neuroprotective mechanism against HIE within 6 hours of birth. ${ }^{11,12}$ However, after 6 hours, neuroprotection is seemingly lost, which minimizes the effectiveness of the treatment and could instead result in adverse effects. ${ }^{9}$ In addition, the infant must be at least 35 weeks' gestation and weigh more than $1800 \mathrm{~g}$ in order to be considered for therapeutic hypothermia.

Therapeutic hypothermia treatments are frequently used to treat neonates with HIE in many developed nations. In the United States, the current procedure for therapeutic hypothermia is whole body cooling in which the infant is placed on a cooling blanket with an esophageal temperature probe inserted into the nose for a total of 72 hours. ${ }^{13,14}$ While on the blanket, the baby is cooled by setting the hypothermia system at $33.5^{\circ} \mathrm{C} .{ }^{15}$ Once the baby reaches a core temperature of $34^{\circ} \mathrm{C}$, cooling is done in a servo manner to reach the target temperature of $33.5^{\circ} \mathrm{C}$ to avoid overcooling. ${ }^{9,16}$ Upon completion of the hypothermic period, a 6-10-hour rewarming process begins, during which the baby is warmed at a gradual rate of $0.5^{\circ} \mathrm{C}$ per hour or less until it reaches a core temperature of $36.5^{\circ} \mathrm{C}$ and stabilizes. ${ }^{11,17}$

Currently, therapeutic hypothermia treatments are not a viable standard of care in developing nations. ${ }^{18}$ Existing treatments are too expensive and have an electricity demand that surpasses the availability of power in many countries. Attempts to develop low-cost, low-energy therapeutic hypothermia devices have been unsuccessful. ${ }^{19}$ Examples of such attempts have included the use of fans in South Africa, which lacked any method of control, and the implementation of cold water bottles around the baby in Uganda, which resulted in overshoot and an increase in side effects (ie, coagulopathy) and mortality. ${ }^{20,21}$

Here, we developed a low-cost, low-power therapeutic hypothermia device for use in developing nations. The target temperature during the cooling stage can be reached within 2 hours, and the requirements for gradual rewarming can be met. In addition, simple control and monitoring systems were implemented to be appropriate for countries without a reliable electricity infrastructure. Utilizing this device in piglet models, we demonstrated the ability to mimic the treatments of more expensive therapies, without using the vast amounts of electricity required by other systems. By reducing the cost of therapeutic hypothermia by more than $99 \%$ compared with existing treatments, this device is a good candidate as a global standard of care for HIE treatment in developing countries.

\section{Materials and methods}

\section{Instrument design}

As shown in Figure 1, our device is mainly composed of two clay pots, sand, urea-based powder, polyethylene covering, styrofoam blocks, a basic microprocessor, and electronics. One inner pot ( 16 inches $\times 12$ inches $\times 6$ inches) is put inside an outer pot (17 inches $\times 13$ inches $\times 9$ inches). Sand and ureabased cooling powder are mixed and placed between the outer and the inner pots. The inner pot with a polyethylene layer on top serves as a vessel in which a neonate with HIE is placed for hypothermia treatment. The microprocessor, thermistors, two AAA batteries, circuit board, and LED lights were used as a temperature monitoring system, which measures rectal and skin temperature of an infant. The total cost of our device is $\$ 31.50$, which is $99 \%$ lower than $\$ 12,000$, which is the cost of current advanced hypothermia devices.

For sanitary purposes, sand should be replaced every 2 months. Urea-based cooling packet powder, which is applied for initial dramatic cooling, is only used one time per patient. When water is added to the mixture of powder and sand, the powder will dissolve and leak through an outer clay pot. For the next time use, a nurse or worker can simply add fresh urea powder to the existing sand in the device. Clay pots can be washed with soap or common cleaning agents and maintained for a year as long as there are no cracks.

\section{Cooling}

Lowering of the neonate's core temperature is achieved through the use of evaporative cooling. Wet sand was placed between two clay pots. As shown in Figure 2, when water is added to the sand, the water particles slowly leave the outer

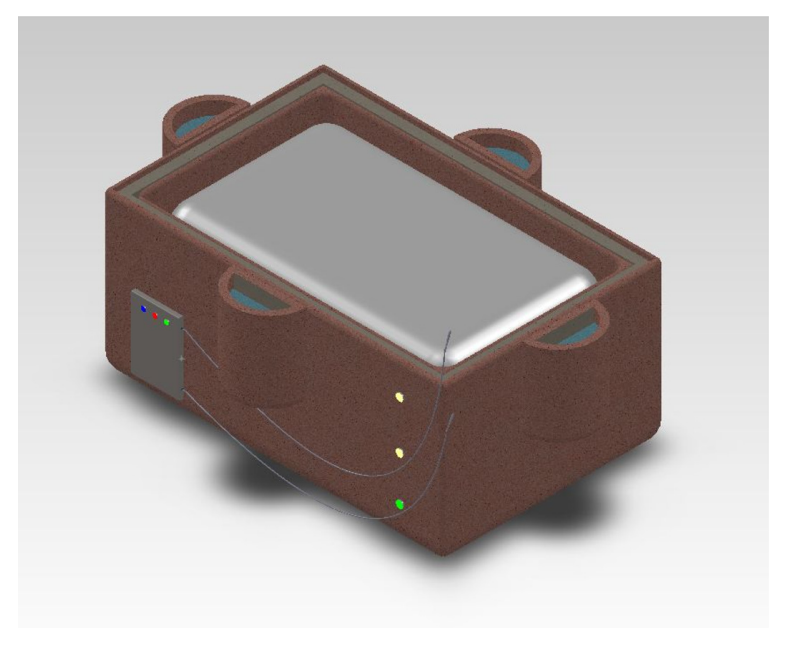

Figure I Computer-aided design of the therapeutic hypothermia device. 


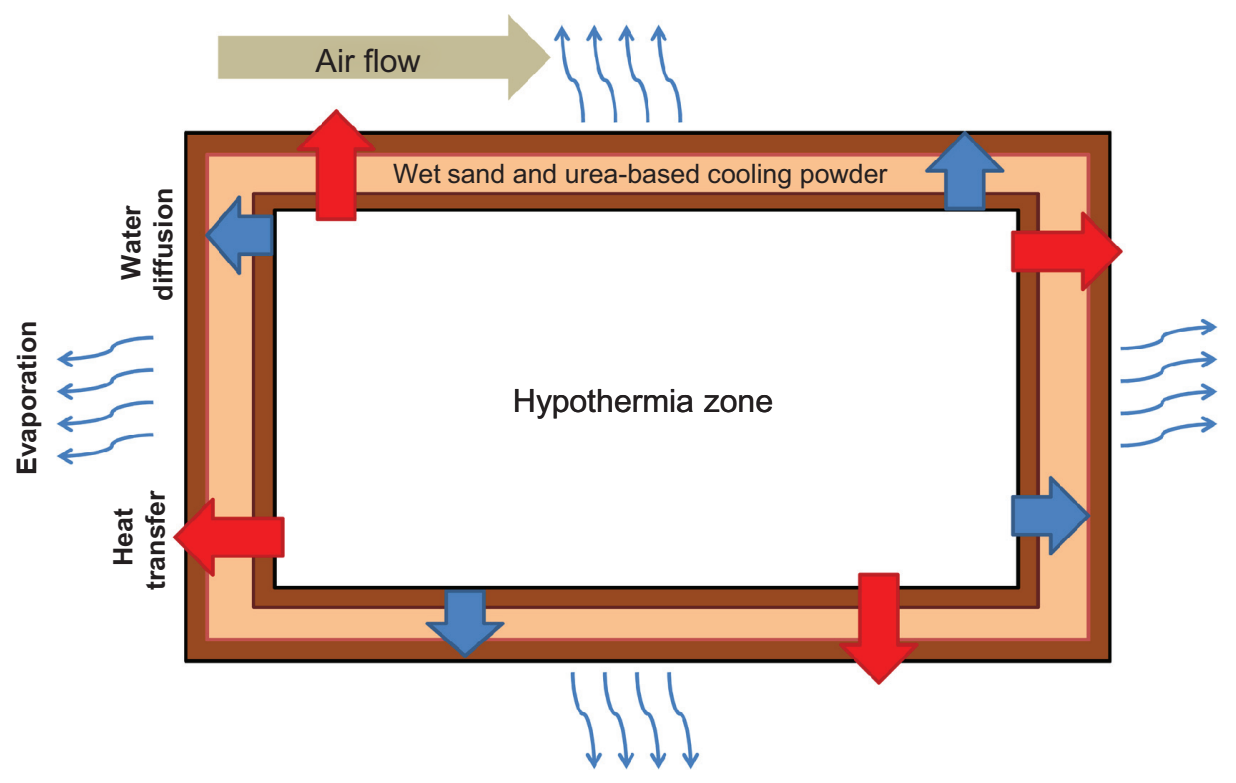

Figure 2 Schematic of cooling.

Note: Temperature changes based on heat transfer, water diffusion, and air flow of the surrounding system.

clay pot through the small pores in the clay. As the water evaporates, heat is drawn from the inner clay pot, resulting in a lower temperature on the inner clay pot surface.

To understand better the heat flow in the system, a schematic was created (Figure 3) to model the pathway of temperature change. Each step was modeled with transfer functions. Through the use of these functions and computer simulations, it was determined that an inner clay pot surface temperature of $17^{\circ} \mathrm{C}$ was sufficient to lower the inner body temperature of the neonate to $33.5^{\circ} \mathrm{C}$. Mathematical models indicated that the decrease in the neonate's temperature would take approximately one and a half hours. In order to validate our model, the cooling mechanism consisting of wet sand between two clay pots was constructed. Water was added to the sand every 12 hours, and the inner pot temperature and room temperature were closely monitored. ${ }^{22}$

\section{Warming}

A maximum rate of warming of $0.5^{\circ} \mathrm{C}$ was required in order to avoid health risks associated with rapid rewarming..$^{23,24}$ Therefore, controlled passive warming was used to reduce the possibility of overshoot in warming. Passive warming allows the rate of temperature increase to occur more gradually, and also reduces the amount of energy required to operate the device.

In order to initiate warming, water is no longer added to the sand. This allows passive warming to occur more readily. Passive warming is controlled by raising and lowering the neonate out of and into the device. In order to raise the neonate's temperature, the neonate is lifted, and a small block is placed underneath the baby inside the inner pot. Raising the neonate lifts it from the cool surface of the clay, allowing the neonate to undergo passive warming. Additional blocks can be added

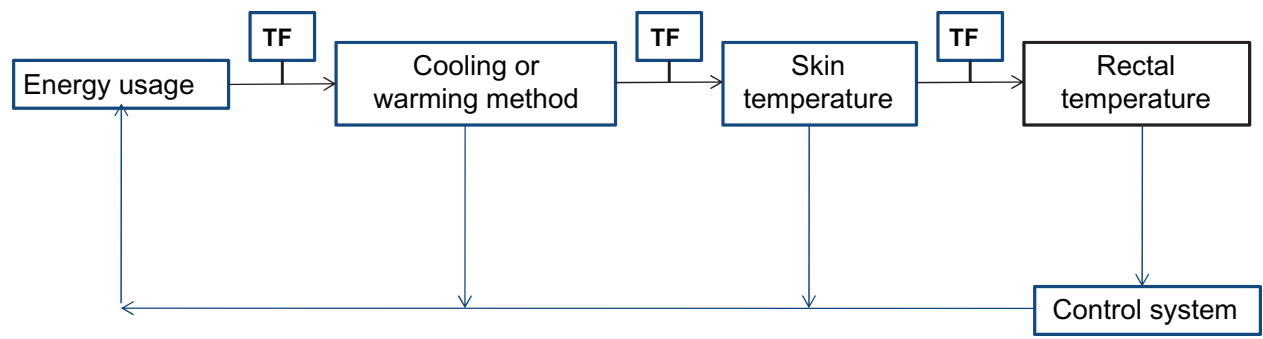

TF $=$ Transfer function

Figure 3 Model of energy flow of device.

Notes: The energy usage is transferred to either the cooling or warming method through a transfer function. The cooling or warming method transfers to a change in skin and rectal temperature. All of the manipulations are controlled via the control system of the device. 
inside the inner pot to increase the warming rate further. On the other hand, to slow down the rate of temperature increase or to maintain a stable cool temperature, blocks can be removed to lower the neonate back to the inner pot. Therefore, lowering or raising the neonate from the inner pot using the blocks allows us to utilize the temperature gradient of the inner pot to regulate the neonate's core body temperature.

Passive warming might not be sufficient for warming a neonate. In this case, an active warming process is required. A simple and cost-effective way to implement active warming is via Kangaroo Mother Care (KMC). ${ }^{25} \mathrm{KMC}$ is a technique promoted by the World Health Organization in which the neonate is held close to the chest of the mother or an attending nurse to allow excessive heat to transfer from the caretaker to the neonate. Should the neonate receiving therapeutic hypothermia treatment require a large increase in temperature, KMC will be applied to the newborn.

\section{Control and monitoring system}

The control system functions primarily through a peripheral interface microcontroller and two types of indicators, ie, green and yellow status LED lights (Figure 4). The microcontroller is programmed in conjunction with an individualized circuit containing thermistors to provide temperature feedback and to help achieve the specific temperature ranges that the neonate must be kept in during the cooling and warming processes. The green LED light will indicate that the baby's core temperature is increasing at a maximum rate of $0.5^{\circ} \mathrm{C}$ per hour, while the yellow LED light means that the baby's core temperature is either falling too low or rising too high (Figure 4). In addition, there are three supplemental LED lights on the side of the outer pot corresponding to three different heights at which the baby may be elevated or lowered (Figure 1). For example, if the baby is cooled too fast, the top LED light will turn on to indicate that the baby needs to be elevated to the maximum height to reduce cooling. On the other hand, if the baby is being warmed at a rate faster than $0.5^{\circ} \mathrm{C}$ per hour, then the middle or the lowest LED light will be turned on to alert a nurse to lower the baby for effective treatment to continue. Our control system, which many developing world devices currently lack, is simple and elegant yet requires minimal input from a nurse. ${ }^{26}$

\section{Validation of device through animal experimentation}

To test the more practical efficacy of our device, three piglets ( $\mathrm{n}=3 ; 2-10$ days old; $1800 \pm 400 \mathrm{~g}$ ), were used in our proofof-concept experiment with the approval of Johns Hopkins Animal Care and Use Committee (Protocol SW11M475) and guidance from staff in the pediatric critical care unit laboratory and the neonatal neurointensive care nursery at Johns Hopkins University School of Medicine. Piglets were used as a model for neonates because the stages of neuronal development are similar to those of a neonate. Piglets were anesthetized by inhalation of 5\% isoflurane in a 70/30 nitrous oxide/oxygen mixture by face mask. A tracheotomy was performed, and the lungs were mechanically ventilated with $1.5 \%$ isoflurane in a 70/30 nitrous oxide/oxygen mixture. A rectal

Digital output from microprocessor (5V)

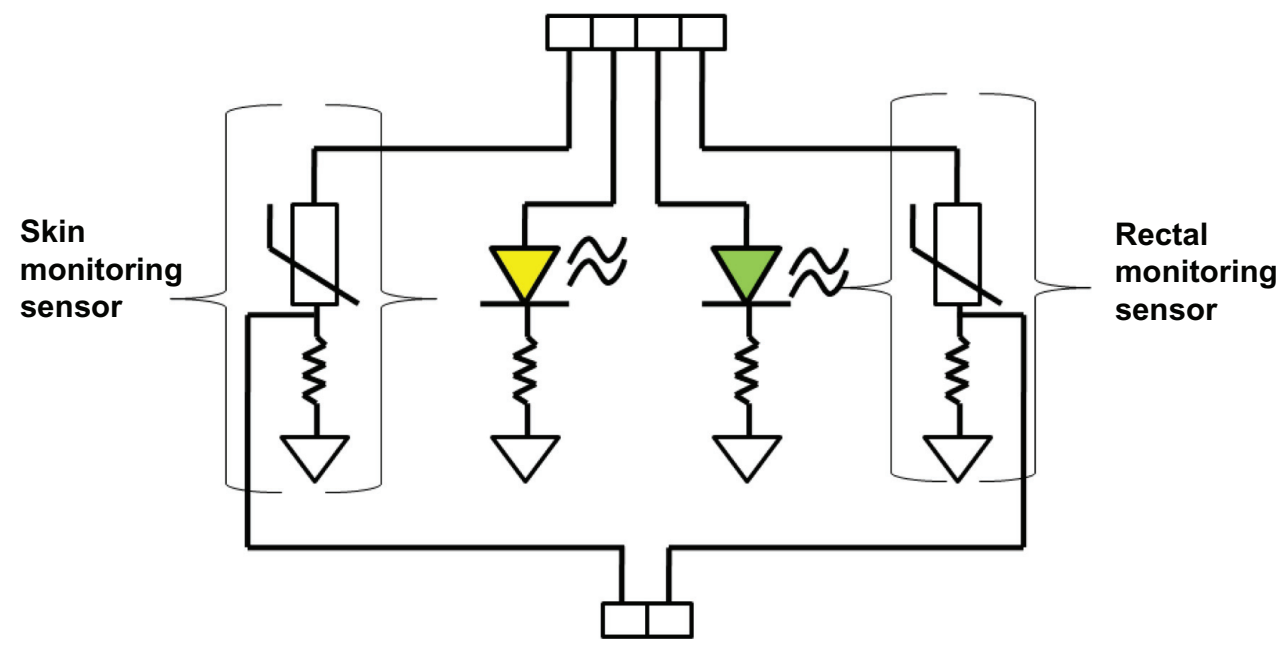

Analog input to microprocessor

Figure 4 Digital output of the control system.

Notes: The skin and rectal thermometers are placed in series. Recordings from these probes result in changes in the respective LED light. 
temperature probe was placed. Piglets underwent aseptic surgery for placement of sterile catheters into the femoral artery and vein through an incision in the groin. A solution of 5\% dextrose and $0.45 \%$ saline was infused at a maintenance rate of $4 \mathrm{~mL} / \mathrm{kg} /$ hour. Pharmaceutical grade fentanyl was infused intravenously at a rate of $20 \mathrm{mg} / \mathrm{kg}+20 \mu \mathrm{g} / \mathrm{kg} / \mathrm{hour}$. Pharmaceutical grade pancuronium was administered intravenously at a rate of $0.2 \mathrm{mg} / \mathrm{kg}+0.2 \mathrm{mg} / \mathrm{kg} /$ hour to facilitate electrocauterization of the muscle layers and to prevent shivering with hypothermia and rewarming. The isoflurane concentration was increased, additional fentanyl boluses of $20 \mu \mathrm{g} / \mathrm{kg}$ were administered, and the fentanyl infusion was increased for animal comfort if the animal's heart rate exceeded 200 beats per minute without any other apparent cause (such as hypoventilation) or if blood pressure or heart rate increased by $10 \%$ or more during surgery (a normal heart rate for a piglet is approximately 140-200 beats per minute).

Throughout testing on the piglets, temperature was checked at least every 10 minutes. To set up the device, sand and half a packet of urea-based cooling powder were mixed and placed in between the two pots. To initiate cooling, $600 \mathrm{~mL}$ of tap water $\left(24^{\circ} \mathrm{C}-39^{\circ} \mathrm{C}\right)$ was added to the sand and urea-based powder layer, with care taken to avoid spilling water into the inner pot. The piglet was cooled until it reached $34^{\circ} \mathrm{C}$, at which point it was elevated fully and a blanket was placed on top for passive warming. Once every half hour, a heating blanket was placed on the piglet for 10 minutes in order to mimic KMC. It was found that 10 minutes of heating allowed the temperature of the piglet to increase at the correct rate. After warming for 10 minutes with the heating blanket, the piglet was placed back in the clay pot. Elevation was changed in order to maintain the new temperature achieved with the heating blanket. Even while the piglet was elevated, an inner pot temperature of $17^{\circ} \mathrm{C}-19^{\circ} \mathrm{C}$ was maintained. If the pot started to warm, more water was added to the sand.

\section{Temperature monitoring}

Figure 4 shows a diagram of the control system circuit. The microprocessor uses a temperature reading from a rectal monitoring sensor to determine which LED light to turn on. A green LED light is turned on if the rectal temperature is within $33.5^{\circ} \mathrm{C} \pm 1{ }^{\circ} \mathrm{C}$ during cooling, while a yellow LED is turned on to warn the nurse that the rectal temperature is not within the desired temperature range. ${ }^{27} \mathrm{~A}$ skin monitoring sensor is used as an additional safeguard to prevent any drastic change in temperature and dangers caused by a failure of rectal monitoring. The skin sensor is placed on a patient's abdomen to make sure that the neonate's skin temperature is not too low or too high. The same indicating LEDs are used to indicate temperature variability to health care providers.

\section{Results \\ Cooling}

By placing wet sand between two clay pots, adding water to the sand, and measuring room and inner pot temperatures, the effectiveness of cooling was determined. Figure 5 demonstrates that the inner pot surface temperature was able to reach $17^{\circ} \mathrm{C}$ within one hour and 30 minutes, which is the target temperature required to cool the neonate down to $33.5^{\circ} \mathrm{C}$ (Supplementary Figure 1 and Supplementary Table 1). In addition, the device maintained this temperature without much variability, even with changes in room temperature, for over 24 hours, at which point the experiment was stopped.

\section{Animal procedures}

With the first piglet subject, only the ability to cool piglets was tested. It was found that the first piglet reached the target rectal temperature in one hour and 45 minutes, approximately matching the mathematical modeling predictions. However, there was an overshoot in cooling, indicating that passive warming is required to prevent overcooling (Figure 6A). The second piglet was used to test elevation as a passive warming method. The target temperature was reached in about 25 minutes. However, the piglet was also underweight. Temperature stabilized at around $30.4^{\circ} \mathrm{C}$ once passive warming had been started, and this temperature was maintained for over 3 hours (Figure 6B).

During the third piglet test, passive warming was started early to prevent the overshoot seen in previous trials. The piglet reached the target temperature of $33.5^{\circ} \mathrm{C}$ around 45 minutes and there was no overshoot in the cooling. Although it was not possible to test $\mathrm{KMC}$ on the piglet due to the animal protocol, we calculated the amount of heat flow required to simulate KMC (Supplementary Figure 2). When the simulation was tested with a heating blanket, it was found that the core temperature was kept constant at the warmer temperature after the application of KMC for 50 minutes. Therefore, the results satisfied our warming constraint of $0.5^{\circ} \mathrm{C}$ per hour (Figure 6C).

\section{Discussion}

We have designed a low-cost and low-energy therapeutic hypothermia device that is able to perform effective whole body cooling in a piglet model. The treatment performed is both accurate and precise, and follows the guidelines set by existing technologies. The results demonstrate that the target temperatures were reached within the first 2 hours after starting treatment, which is well within the acceptable 
A
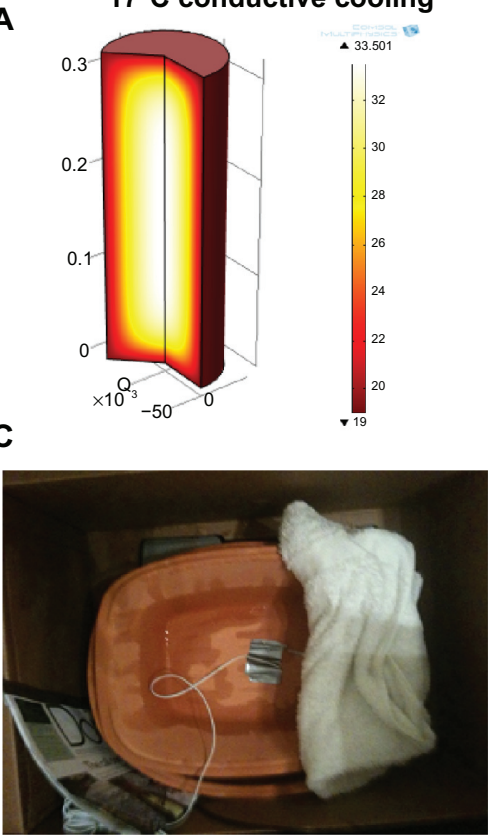

B

\begin{tabular}{|c|c|c|}
\hline $\begin{array}{c}\text { Conductive } \\
\text { cooling temp } \\
\left({ }^{\circ} \mathrm{C}\right)\end{array}$ & $\begin{array}{c}\text { Core temp }\left({ }^{\circ} \mathrm{C}\right) \\
\text { of baby }\end{array}$ & $\begin{array}{c}\text { Time } \\
\text { required for } \\
\text { cooling }\end{array}$ \\
\hline 17 & 33.5 & $\mathbf{1 ~ h r ~ 2 0 ~} \mathbf{~ i n}$ \\
\hline 19 & 33.5 & $2 \mathrm{hr}$ \\
\hline 23 & 35 & $5 \mathrm{hr} 30 \mathrm{~min}$ \\
\hline
\end{tabular}

D

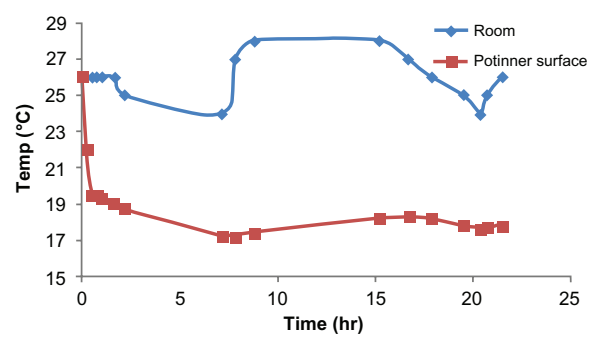

Figure 5 Verification of inner pot temperature. Utilizing modeling techniques, a temperature of $17^{\circ} \mathrm{C}$ was established as being capable of cooling the neonate to $33.5^{\circ} \mathrm{C}$ within one hour and 20 minutes (A and $\mathbf{B})$. This was verified (C and $\mathbf{D})$ via testing.

A

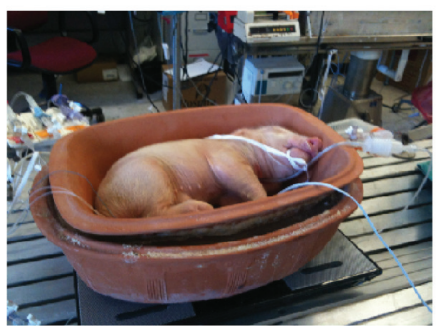

B

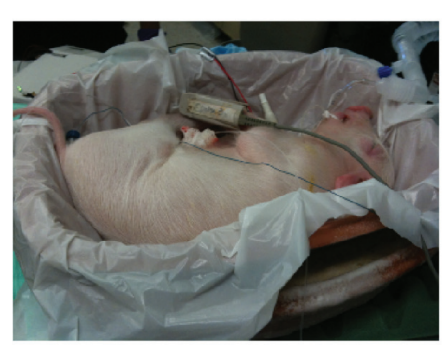

C

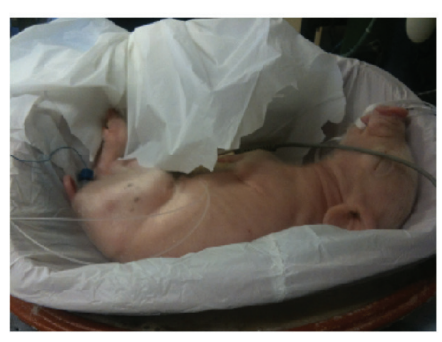

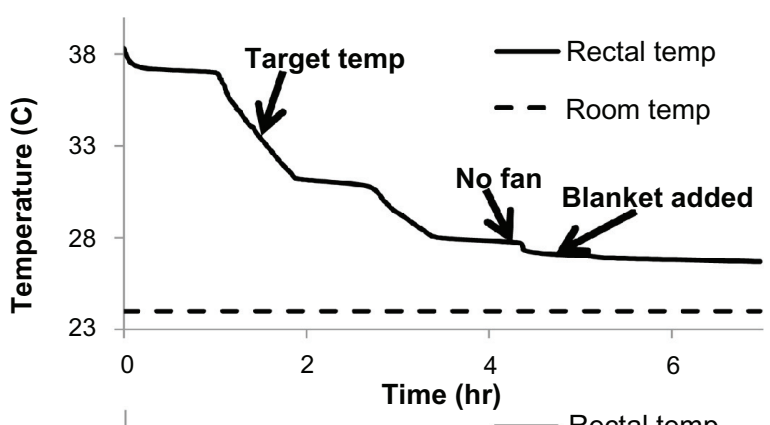
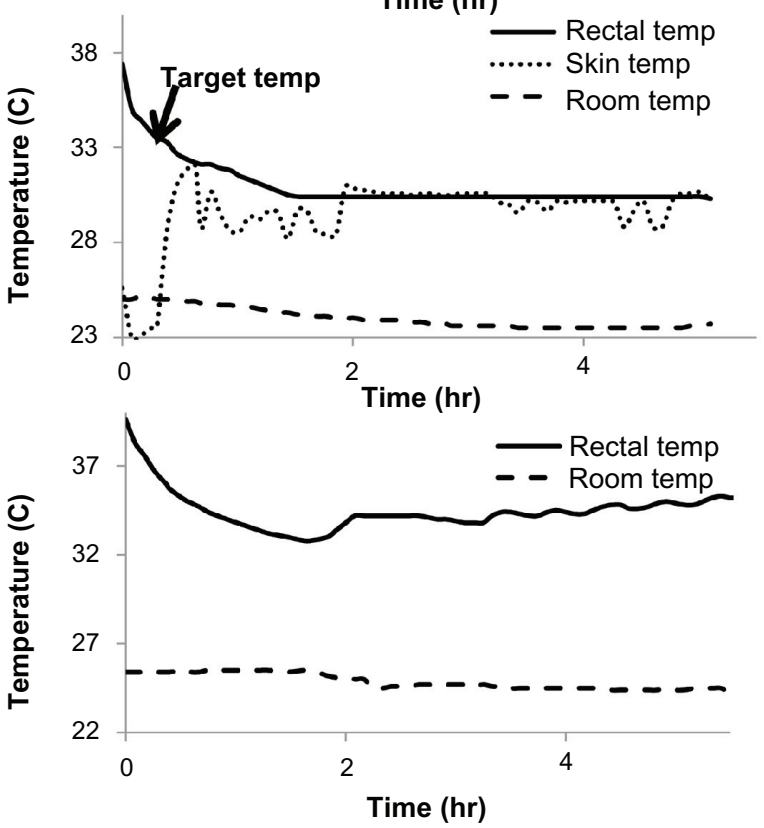

Figure 6 Piglet model results. (A) Demonstrates the rapid cooling of the piglet within the modeling parameters. However, because there was overshoot, passive warming was required during the cooling process. (B) Demonstrates sustained temperature for over 3 hours. (C) Demonstrates effective warming rate of $0.5^{\circ} \mathrm{C}$ per hour. 
time frame of 6 hours. This temperature was maintained in the live models for up to 3 hours, with no indication that there would be any change over longer periods of times. Variation in the temperature was controlled within a $1^{\circ} \mathrm{C}$ margin of error. Additionally, the device was able to rewarm the baby at the required rate of $0.5^{\circ} \mathrm{C}$ per hour.

In our study, there was variability in the amount of time it took to cool the piglet down. This variability can be attributed to the variation in mass of each piglet. Because the masses were highly variable, it is likely that this played a role in the amount of time it took to cool down the piglets. In addition, because cooling down the neonate quickly is important, a urea-based cold pack was mixed in with the sand during the second and third trials in order to speed up the cooling process. This did not affect the final temperatures, but did decrease the time taken to reach $17^{\circ} \mathrm{C}$ (Figure 6C). The efficiency of cooling was found to not be affected by the surrounding ambient temperature, because the ambient temperature did not significantly affect the rate of evaporation (Figure 5D). In addition, the temperature of the water added to the sand did not affect the final temperature that the pot reached, and had little impact on the amount of time the device took to reach that temperature (Supplementary Table 2). However, humidity should be tested for its effects on the cooling aspect of the device.

We used isoflurane as an anesthetic as an additional precaution in preventing harm to the piglets. Nitrous oxide was added to prevent animal discomfort. For future studies, the device will be tested with a more clinically relevant sedation method, such as opiate infusion, in order to more closely mimic what would be found in the clinical setting. Paralysis was initiated in order to prevent the piglets from shivering by lowering the thermoregulatory set point. This will prevent resistance to the temperature changes that therapeutic hypothermia treatment intends to achieve. A piglet experiment with intermittent paralysis or without paralysis will also be performed.

Unlike many other techniques of inducing neonatal hypothermia, our device makes use of whole body cooling. When only the head is cooled, a temperature gradient forms and the temperature of the neonate's brain becomes hard to measure noninvasively, resulting in inaccurate measurements of brain temperature. ${ }^{28}$ This makes therapeutic hypothermia treatment less efficient, and can lead to adverse events. However, with whole body cooling, the entire body temperature of the neonate is lowered. This has two benefits. First, it reduces the presence of a temperature gradient in the brain. In addition, because the whole body is cooled at the same rate, it is easier to measure internal body temperature by rectal monitoring, which gives an accurate depiction of the temperature in the brain. ${ }^{29}$

To ensure that the device is safe for use with neonates, biocompatibility of the materials was analyzed. Clay is biocompatible in neonates. Having the neonates in a moist environment does increase the risk of infection. Therefore, care must be taken to avoid spilling any water into the clay pots, and to make sure that none of the sand leaves the gap between the two pots. Any coverings placed over or on the device to prevent cracking will be made of polyethylene, which is safe for use around neonates. A significant concern is that the pots might crack during use, and that this could harm a neonate. Therefore, increasing pot thickness is being analyzed as a possible method to prevent fractures.

Warming was achieved through a combination of passive and active techniques. The prevention of further cooling and the ability to maintain specific temperatures was demonstrated with the passive technique of raising and lowering the neonate. This allowed for the control required to raise the temperature at a maximum rate of $0.5^{\circ} \mathrm{C}$ per hour. Active warming was used to raise the temperature when passive warming was not sufficient. In the animal experiments, active warming was performed using a heated blanket. However, in clinical studies, this warming should be provided using KMC. Because there are likely to be differences between the method used for testing and the $\mathrm{KMC}$ technique, $\mathrm{KMC}$ should be studied further in order to ensure that the same degree of controllability exists with KMC as with the heated blanket.

The monitoring and control system met the required precision of a $1^{\circ} \mathrm{C}$ margin of error, and allowed for clinically acceptable monitoring of temperature. The LED lights indicating overheating and overcooling worked, and are a simple method for health care workers to assess the current status of the neonate placed in the device. Because overshoot can increase the risk of mortality and morbidity, it is essential that the control and monitoring system be proficient. Currently, the design requires the presence of a nurse or attending health care worker in order for changes in temperature to be made. Automation of the system would be ideal; however, this poses a significant challenge due to electricity requirements. Therefore, making the control system as self-sustained and the device as inclusive as possible is important in order to facilitate the task of treating neonates with this device.

One of the major problems with existing devices is cost. By using materials readily available at low cost in developing countries, a final cost of about $\$ 30$ is predicted for this device (Supplementary Table 3). This makes our device a viable product for the treatment of HIE in the developing world. 
In conclusion, this study demonstrates the ability of our device to cool down a piglet and then rewarm it, following the guidelines set by the standard of care that exists for technologies in developed countries. This device has the potential to be a valuable treatment to reduce the impact of HIE in the developing world. Nevertheless, we believe that this device should not be introduced into clinical practice in any country without data from carefully designed prospective trials that have been approved by regional ethical or clinical research committees and the US Food and Drug Administration for trials in the United States, given the potential of overcooling to cause increased morbidity in this fragile group of neonates, as has happened before in a previous trial. ${ }^{20}$

\section{Acknowledgments}

We thank Samrie Beshah, Winston Aw, Kalyna Apkarian, and Melissa Sajnani for their assistance in testing and designing, and for their valuable suggestions. We appreciate Dr. Frances Northington, Director of the Johns Hopkins Neuro-intensive Care Nursery and a nurse, and Charlamaine Parkinson for their valuable clinical inputs. Lastly, we thank Dr. Youseph Yazdi, and the Center for Bioengineering Innovation and Design for invaluable discussion for design process. Publication of this article was funded in part by the Open Access Promotion Fund of the Johns Hopkins University Libraries.

\section{Disclosure}

There are no conflicts of interest in any contents of this manuscript.

\section{References}

1. Cooper DJ. Induced hypothermia for neonatal hypoxic-ischemic encephalopathy: pathophysiology, current treatment, and nursing considerations. Neonatal Netw. 2011;30(1):29-35.

2. Brann AW Jr. Hypoxic ischemic encephalopathy (asphyxia). Pediatr Clin North Am. 1986;33(3):451-464.

3. Merrill L. Therapeutic hypothermia to treat hypoxic ischemic encephalopathy in newborns: implications for nurses. Nurs Womens Health. 2012;16(2):126-134.

4. Ten VS, Starkov A. Hypoxic-ischemic injury in the developing brain: the role of reactive oxygen species originating in mitochondria. Neurol Res Int. 2012;2013:642976.

5. Shankaran S, Barnes PD, Hintz SR, et al. Brain injury following trial of hypothermia for neonatal hypoxic-ischaemic encephalopathy. Arch Dis Child Fetal Neonatal Ed. 2012;97(6): F398-F404.

6. Sabir H, Scull-Brown E, Liu X, Thoresen M. Immediate hypothermia is not neuroprotective after severe hypoxia-ischemia and is deleterious when delayed by 12 hours in neonatal rats. Stroke. 2012;43(12): 3364-3370.

7. Gancia P, Pomero G. Therapeutic hypothermia in the prevention of hypoxic-ischaemic encephalopathy: new categories to be enrolled. Journal of Maternal-Fetal and Neonatal Medicine. 2012;25(S4):86-88.

8. Shankaran S, Pappas A, McDonald SA, et al. Childhood outcomes after hypothermia for neonatal encephalopathy. N Engl J Med. 2012;366(22): 2085-2092.
9. Azzopardi DV, Strohm B, Edwards AD, et al. Moderate hypothermia to treat perinatal asphyxial encephalopathy. N Engl J Med. 2009;361(14): $1349-1358$

10. Gluckman PD, Wyatt JS, Azzopardi D, et al. Selective head cooling with mild systemic hypothermia after neonatal encephalopathy: multicentre randomised trial. Lancet. 2005;365(9460):663-670.

11. Chakkarapani E, Thoresen M. Use of hypothermia in the asphyxiated infant. Perinatology. 2010;3:20-29.

12. Johnston MV, Fatemi A, Wilson MA, Northington F. Treatment advances in neonatal neuroprotection and neurointensive care. Lancet Neurol. 2011;10(4):372-382.

13. Laura F, Mori A, Tataranno ML, et al. Therapeutic hypothermia in a late preterm infant. J Matern Fetal Neonatal Med. 2012;25 Suppl 1: $125-127$.

14. Ma H, Sinha B, Pandya RS, et al. Therapeutic hypothermia as a neuroprotective strategy in neonatal hypoxic-ischemic brain injury and traumatic brain injury. Curr Mol Med. 2012.

15. Natarajan G, Pappas A, Shankaran S, et al. Effect of inborn vs outborn delivery on neurodevelopmental outcomes in infants with hypoxicischemic encephalopathy: secondary analyses of the NICHD wholebody cooling trial. Pediatr Res. 2012;72(4):414-419.

16. Johnston ED, Becher JC, Mitchell AP, Stenson BJ. Provision of servocontrolled cooling during neonatal transport. Arch Dis Child Fetal Neonatal Ed. 2012;97(5):F365-F367.

17. Thoresen M, Whitelaw A. Cardiovascular changes during mild therapeutic hypothermia and rewarming in infants with hypoxicischemic encephalopathy. Pediatrics. 2000;106(1 Pt 1):92-99.

18. Joolay Y, Harrison MC, Horn AR. Therapeutic hypothermia and hypoxic ischemic encephalopathy: opinion and practice of pediatricians in South Africa. J Perinat Med. 2012;40(4):447-453.

19. Horn A, Thompson C, Woods D, et al. Induced hypothermia for infants with hypoxic-ischemic encephalopathy using a servocontrolled fan: an exploratory pilot study. Pediatrics. 2009;123(6): e1090-e1098.

20. Robertson NJ, Nakakeeto M, Hagmann C, et al. Therapeutic hypothermia for birth asphyxia in low-resource settings: a pilot randomised controlled trial. Lancet. 2008;372(9641):801-803.

21. Kumar V, Shearer JC, Kumar A, Darmstadt GL. Neonatal hypothermia in low resource settings: a review. J Perinatol. 2009;29(6): 401-412.

22. Jacobs S, Hunt R, Tarnow-Mordi W, Inder T, Davis P. Cooling for newborns with hypoxic ischaemic encephalopathy. Cochrane Database Syst Rev. 2007;4:CD003311.

23. Polderman KH. Induced hypothermia and fever control for prevention and treatment of neurological injuries. Lancet. 2008;371(9628): 1955-1969.

24. Maxwell WL, Watson A, Queen R, et al. Slow, medium, or fast re-warming following post-traumatic hypothermia therapy? An ultrastructural perspective. J Neurotrauma. 2005;22(8): 873-884.

25. Charpak N, Ruiz-Pelaez JG, Figueroa de Calume Z. Current knowledge of Kangaroo Mother Intervention. Curr Opin Pediatr. 1996;8(2):108-112.

26. Landry MA, Doyle LW, Lee K, Jacobs SE. Axillary temperature measurement during hypothermia treatment for neonatal hypoxicischaemic encephalopathy. Arch Dis Child Fetal Neonatal Ed. May 3, 2012.

27. Duru CO, Akinbami FO, Orimadegun AE. A comparison of tympanic and rectal temperatures in term Nigerian neonates. BMC Pediatr. 2012; 12:86.

28. Shankaran S, Laptook AR, Ehrenkranz RA, et al. Whole-body hypothermia for neonates with hypoxic-ischemic encephalopathy. N Engl J Med. 2005;353(15):1574-1584.

29. Sarkar S, Donn SM, Bapuraj JR, Bhagat I, Barks JD. Distribution and severity of hypoxic-ischaemic lesions on brain MRI following therapeutic cooling: selective head versus whole body cooling. Arch Dis Child Fetal Neonatal Ed. 2012;97(5):F335-F339. 


\section{Supplementary materials}
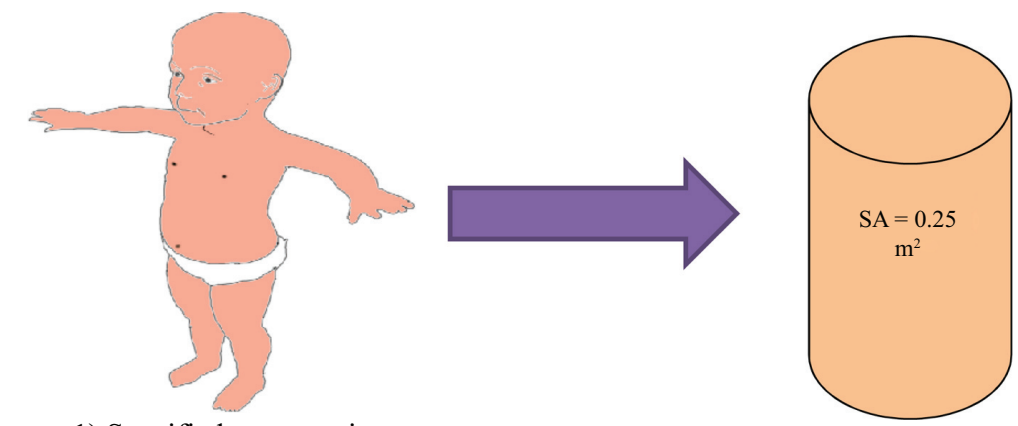

1) Specific heat capacity:

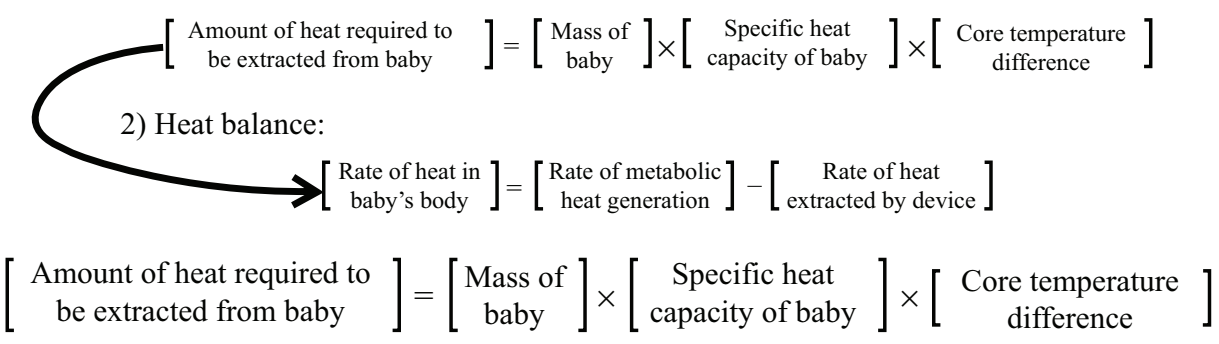

To cool a neonate from $37^{\circ} \mathrm{C}$ to $35.5^{\circ} \mathrm{C}$

$$
\begin{gathered}
=3500 \mathrm{~J} / \mathrm{kg}{ }^{\circ} \mathrm{C} \times 2.5 \mathrm{~kg} \times 3.5^{\circ} \mathrm{C} \\
=30625 \text { Joules }
\end{gathered}
$$

Average food calorie intake for neonate $=400$ calories per day

Generation of metabolic heat $=\frac{\mathrm{dQ}_{\text {meta }}}{\mathrm{dt}}=\frac{4 \times 10^{5} \mathrm{cal} \times 4.184 \frac{\mathrm{J}}{\mathrm{cal}}}{86400 \mathrm{~s}}=19.37 \mathrm{~W}$

$$
\left[\begin{array}{c}
\text { Rate of heat in } \\
\text { baby's body }
\end{array}\right]=\left[\begin{array}{c}
\text { Rate of metabolic } \\
\text { heat generation }
\end{array}\right]-\left[\begin{array}{c}
\text { Rate of heat } \\
\text { extracted by device }
\end{array}\right]
$$

$$
\frac{\mathrm{dQ}_{\text {body }}}{\mathrm{dt}}=\frac{\mathrm{dQ}_{\text {meta }}}{\mathrm{dt}}=\frac{\mathrm{dQ}_{\text {cond }}}{\mathrm{dt}}
$$

where $\mathrm{Q}_{\text {body }}$ is the heat in baby's body, $\mathrm{Q}_{\text {meta }}=$ Metabolic heat, and $\mathrm{Q}_{\text {cond }}=$ Heat extracted by conduction

$$
\frac{\mathrm{dQ}_{\text {body }}}{\mathrm{dt}}=\frac{\mathrm{dQ}_{\text {meta }}}{\mathrm{dt}}-\mathrm{kSA} \frac{\Delta \mathrm{T}}{\mathrm{d}}
$$

$\mathrm{SA}=$ Surface area, $\mathrm{k}=$ Thermal conductivity of a blanket, and $\mathrm{d}=$ Thickness

$$
\begin{gathered}
\frac{\mathrm{d}}{\mathrm{dt}} \Delta \mathrm{T}=\frac{1}{\mathrm{mC}_{\mathrm{p}}}\left(\frac{\mathrm{dQ}_{\text {meta }}}{\mathrm{dt}}-\frac{\mathrm{kSA}}{\mathrm{d}} \Delta \mathrm{T}\right) \\
\text { Define } \frac{1}{\tau}=\frac{\mathrm{kSA}}{\mathrm{dmC}_{\mathrm{p}}} \\
\frac{\mathrm{d}}{\mathrm{dt}} \Delta \mathrm{T}+\frac{1}{\tau} \Delta \mathrm{T}=\frac{1}{\mathrm{mC}_{\mathrm{p}}}\left(\frac{\mathrm{dQ}_{\text {meta }}}{\mathrm{dt}}\right)
\end{gathered}
$$

This is the first ordinary linear differential equation

$$
\Delta \mathrm{T}(\mathrm{t})=\frac{\tau}{\mathrm{mC}_{\mathrm{p}}}\left(\frac{\mathrm{dQ}_{\text {meta }}}{\mathrm{dt}}\right)+\left[\Delta \mathrm{T}(0)-\frac{\tau}{\mathrm{mC}_{\mathrm{p}}}\left(\frac{\mathrm{dQ}_{\text {meta }}}{\mathrm{dt}}\right)\right] \mathrm{e}^{-\mathrm{t} / \tau}
$$

Figure SI Demonstrating the cooling requirements.

Note: These equations demonstrate the amount of energy required to cool a neonate given metabolic generation and surface area approximations. 


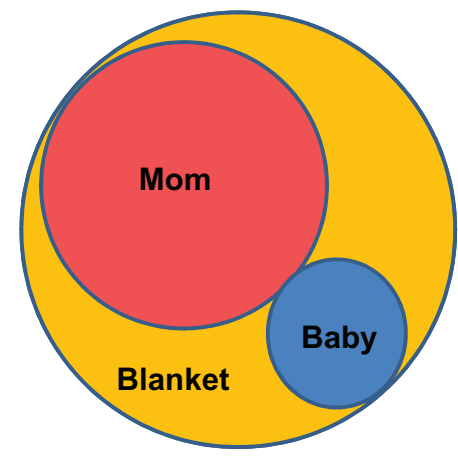

Top view

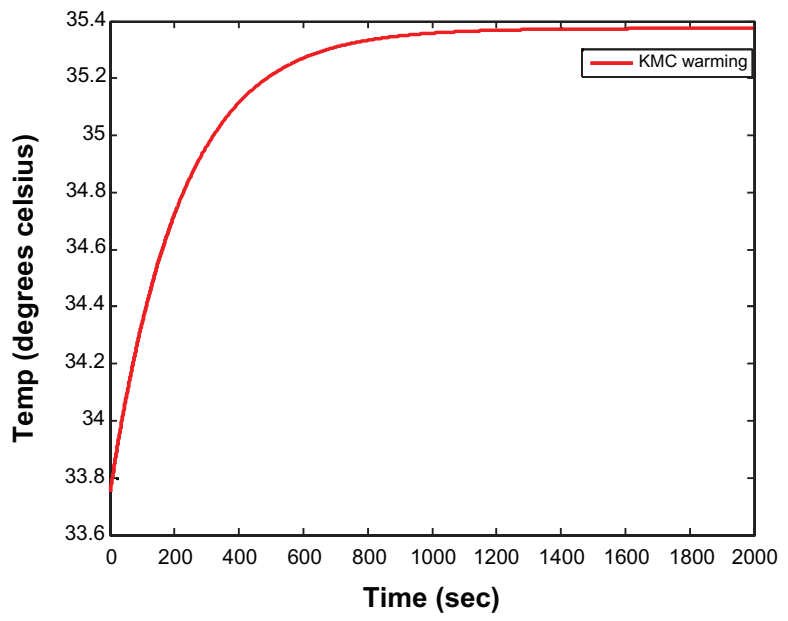

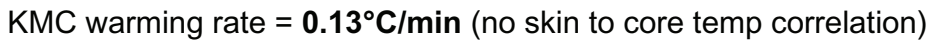

Required warming rate: $0.01^{\circ} \mathrm{C} / \mathrm{min}$

Figure S2 Demonstrating the effectiveness of KMC.

Table SI Simulation data of conductive cooling using the heat flux equations in Supplementary Figure I

\begin{tabular}{lll}
\hline $\begin{array}{l}\text { Conductive cooling } \\
\text { temp }\left({ }^{\circ} \mathbf{C}\right)\end{array}$ & $\begin{array}{l}\text { Core temp }\left({ }^{\circ} \mathrm{C}\right) \\
\text { of baby }\end{array}$ & $\begin{array}{l}\text { Time required } \\
\text { for cooling }\end{array}$ \\
\hline 17 & 33.5 & $\mathrm{I} \mathrm{hr} 20 \mathrm{~min}$ \\
19 & 33.5 & $2 \mathrm{hr}$ \\
23 & 35 & $5 \mathrm{hr} 30 \mathrm{~min}$ \\
\hline
\end{tabular}

Note: It takes about one hour and 20 minutes to reach 33.5 of neonate's body temperature at $17^{\circ} \mathrm{C}$ conductive cooling.
Table S2 Modeling varying initial temperatures of water with final temperature of inner pot

\begin{tabular}{ll}
\hline Initial water temperature $\left({ }^{\circ} \mathbf{C}\right)$ & Final water temperature $\left({ }^{\circ} \mathbf{C}\right)$ \\
\hline 24 & 13 \\
29 & 14 \\
33 & 15 \\
37 & 17 \\
39 & 17
\end{tabular}

Notes: With the help of Ammonium Nitrate, the water temperature can be maintained between $13^{\circ} \mathrm{C}-17^{\circ} \mathrm{C}$ when the initial water temperature varies from $24^{\circ} \mathrm{C}-39^{\circ} \mathrm{C}$.

Table S3 Current cost of device

\begin{tabular}{lll}
\hline Component & Cost & Supplier \\
\hline 2 Ceramic pots & $\$ 4.00$ & Indian Pot Suppliers \\
Sand & $\$ 0.61$ & Logistic Chemisols \\
Scissor stand & $\$ 10$ & Brilife (Shanghai) International Trading Co, Ltd \\
Microprocessor with analog to digital convertor & $\$ 10.39$ & Shenzhen Shijibaike Electronics Co, Ltd \\
Circuit board & $\$ 0.50$ & Shenzhen Hongmy Precision Circuit Co, Ltd \\
Medical grade thermisters & $\$ 2.00$ & Zhaoqing Exsense Electronics Technology Co, Ltd \\
Cotton blanket & $\$ 1.40$ & Shanghai Baby Products \\
5 hours of semi-skilled labor (soldering, sewing, wiring, etc) & $\$ 0.45$ & Pooja Group \\
Cotton fabric & $\$ 1.97$ & Crafty Cuts \\
LLDPE coating & $\$ 0.03$ & Fortune Plastics \\
Teflon coating & $\$ 0.25$ & Suzhou Brisun Trading Co \\
Total cost of device & $\$ 31.60$ & \\
\hline
\end{tabular}

Medical Devices: Evidence and Research

\section{Publish your work in this journal}

Medical Devices: Evidence and Research is an international, peerreviewed, open access journal that focuses on the evidence, technology, research, and expert opinion supporting the use and application of medical devices in the diagnosis, treatment and management of clinical conditions and physiological processes. The identification of novel

\section{Dovepress}

devices and optimal use of existing devices which will lead to improved clinical outcomes and more effective patient management and safety is a key feature. The manuscript management system is completely online and includes a quick and fair peer-review system. Visit http://www. dovepress.com/testimonials.php to read real quotes from authors. 